Published in final edited form as:

Eur J Neurosci. 2019 April ; 49(7): 938-947. doi:10.1111/ejn.13917.

\title{
Synaptic Organization of the Dorsal Lateral Geniculate Nucleus
}

\author{
Martha Bickford \\ Anatomical Sciences and Neurobiology, University of Louisville, Louisville, KY, 40292, USA
}

\begin{abstract}
A half century after Ray Guillery's classic descriptions of cell types, axon types, and synaptic architecture of the dorsal lateral geniculate nucleus, the functional organization of this nucleus, as well as all other thalamic nuclei, is still of enormous interest. This review will focus on 2 classic papers written by Ray Guillery: " A study of Golgi preparations from the dorsal lateral geniculate nucleus of the adult cat", and "The organization of synaptic interconnections in the laminae of the dorsal lateral geniculate nucleus of the cat', as well as the studies that most directly followed from the insights these landmark manuscripts provided. It is hoped that this review will honor Ray Guillery by encouraging further investigations of the synaptic organization of the dorsal thalamus.
\end{abstract}

\section{Graphic Abstract}

In the 1960's, Ray Guillery first described cell types in the dorsal lateral geniculate nucleus (dLGN) and their synaptic organization. These classic papers are reviewed, as well as the studies that most directly followed from his insights. The electron micrograph illustrates some of the dLGN elements originally characterized by Ray Guillery (green: retinogeniculate terminal, purple: interneuron dendritic terminal, red: GABAergic axon terminal, yellow: corticogeniculate terminal of terminal of brainstem origin, blue: thalamocortical cell dendrite. Scale bar $=1-\mathrm{m}$.

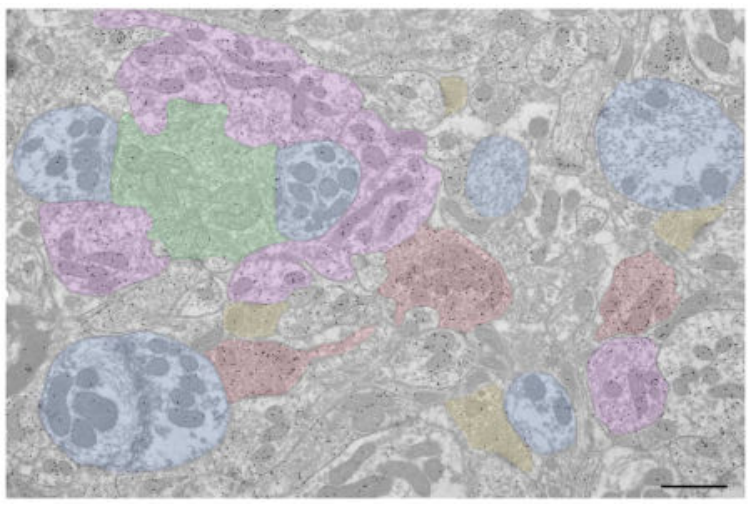

The classification of cell and terminal types is a critical first step for investigations of circuit function. Thus, the classics, " $A$ study of Golgi preparations from the dorsal lateral geniculate nucleus of the adult cat (Guillery 1966), and "The organization of synaptic

"Correspondence: Martha Bickford, martha.bickford@louisville.edu, Department of Anatomical Sciences \& Neurobiology, University of Louisville, School of Medicine 511, South Floyd, Room 111, Louisville, KY 40202.

Conflict of interest: The author declares no competing financial interests. 
interconnections in the laminae of the dorsal lateral geniculate nucleus of the cat' (Guillery 1969a), set the stage for the myriad of subsequent studies of the dorsal lateral geniculate nucleus (dLGN). In fact, investigations of most thalamic circuits have built upon the insights provided by these elegant works. I have personally contemplated these landmark publications countless times as I have perused brain tissue using light or electron microscopes, imagining the excitement that Ray Guillery must have felt in recognizing the morphological characteristics of cell types, ultrastructural features of distinct groups of synaptic terminals, and the unique synaptic patterns that they form. This short review will focus on these 2 classic papers, and the studies that most directly built upon the solid backbone they provided. The review will primarily highlight studies of the cat dLGN, with reference to other species noted where appropriate. It is hoped that this review will honor Ray Guillery by encouraging further investigations of the synaptic organization of the dorsal thalamus.

\section{dLGN cell types defined by Guillery: Class I-IV}

Over 50 years ago, Guillery (1966) defined 4 classes of neurons in the cat dLGN using observations gleaned from Golgi preparations. Class I cells were distinguished by their large size and their smooth or spiny radiating dendrites, which often crossed laminar borders of the dLGN. Class II cells were smaller, with dendritic arbors confined to one lamina of the dLGN. In contrast to the robust dendrites of the class I cells, the dendrites of class II cells were noted to be thin and tortuous, with numerous "claw-like" or "grape-like", appendages. Class III cells were discerned to be the smallest cells in the dLGN. These cells displayed compact dendritic arbors oriented perpendicular to the laminar borders within the dLGN. The dendrites of class III cells extended numerous dendritic appendages; these appendages are distinct from those that arise from class II cells in that they arise from extremely thin stalks. Finally, class IV cells were noted as cells of medium size, located exclusively in the C laminae of the dLGN. Class IV cells typically exhibited a spindleshaped soma and fine, wavy or beaded dendrites, with variable numbers of spine-like protrusions, oriented parallel to the laminar borders.

These 4 cell classes have been validated in numerous ways in that the unique morphological characteristics recognized by Guillery were subsequently correlated with physiological properties (Friedlander et al. 1981), axonal projection patterns (Humphrey et al. 1985a, 1985b), neurotransmitter content (Fitzpatrick et al. 1984; Montero and Zempel 1985; Montero 1986a), cytoskeletal arrangement (Bickford et al. 1998), receptor and other protein expression patterns (Stichel et al. 1988; Sur et al. 1988; Demeulemeester et al. 1991; Godwin et al. 1996; Carden and Bickford 1999; Plummer et al. 1999), as well as the organization of synaptic inputs (Wilson et al. 1984; Hamos et al. 1985; Raczkowski et al. 1988).

\section{dLGN axon types defined by Guillery: Type I-III}

Using observations of Golgi preparations, Guillery (1966) also defined 3 types of axons in the cat dLGN. Type I axons were characterized as very thin axons that extend short side branches which end in small boutons. Their cortical origin was inferred by the ability to 
trace these axons to the optic radiation. Type II axons were characterized as thicker axons that formed restricted clusters of large boutons. Their retinal origin was inferred by the ability to trace these axons to the optic tract, and by the fact that their terminal arbors were confined to a single lamina. The extrinsic origin of both type I and type II axons was also deduced by the fact the none of these axon types could be traced to Golgi-stained geniculate neurons. In contrast, type III axons were defined as intrinsic axons because they could be seen to originate from class III cells. These axons gave off simple boutons or en passant swellings in the vicinity of the class III cells. The predicted origins of these three distinct axons types in the dLGN were subsequently confirmed via tract tracing and intracellular/ axonal fills (e.g. Robson and Mason 1979; Robson 1984; Hamos et al. 1985, 1987; Murphy et al. 2000).

Remarkably, these three morphological axon types have been identified in nearly all thalamic nuclei. This similarity in the innervation patterns found across thalamic nuclei particularly influenced Guillery's later work, and formed the basis of the highly influential driver/modulator framework of thalamic circuits (Sherman and Guillery 1998). Within this framework, Guillery's type II axons are defined as "drivers", which provide the primary excitatory drive for the relay of information to cortex, while Guillery's type I axons are defined as "modulators", which alter the gain of signal transmission. This organizing principle promoted the identification of "first order" and "higher order" thalamic nuclei, based on the origin of their driving inputs (Guillery and Sherman 2002), and additional nucleus-specific terminal configurations continue to be defined (reviewed in Bickford 2016). Thus, Guillery's original descriptions of axon morphology continue to guide our understanding of the dorsal thalamus.

\section{dLGN terminal ultrastructure defined by Guillery: RLP, RSD, F1 and F2}

Guillery (1969a) used a variety of aldehyde fixative solutions to preserve dLGN tissue for electron microscopy; although all synaptic vesicles likely have a spherical shape in vivo (Nakajima and Reese 1983), the aldehyde fixation process causes some vesicles to be preserved with a round shape, while other are preserved with a more flattened or pleomorphic configuration. Conveniently, the distinct vesicle shapes induced by chemical fixation provided the basis for dividing thalamic terminals into those that contained round vesicles ( $\mathrm{R}$ profiles) or flattened vesicles (F profiles). In 1969, several ultrastructural investigations of the dorsal thalamus had been carried out, and synaptic terminals had been characterized (Szentagothai 1963; Majorossy et al. 1965; Majorossy and Réthelyi 1968; Ralston 1969; Ralston and Herman 1969). However, distinctions in vesicle shape were not routinely noted, and therefore resulted in different characterization schemes. Guillery specifically discussed the fact that, while the use of aldehyde fixation may produce artificial changes in vesicle shape, these changes are useful for classification of dLGN circuits because they are consistently observed.

$\mathrm{R}$ profiles were further divided based on size and the ultrastructure of the mitochondria. Large profiles with round vesicles and pale mitochondria (clear matrix between sparse mitochondrial cristae, asterisks in Figures 1-3) were defined as RLP profiles (green profiles in Figures 1B and 3A,B), and small profiles with round vesicles and dark mitochondria 
(dense matrix between compact cristae) were named RSD profiles (yellow profiles in Figure $1 \mathrm{~B}$ and $3 \mathrm{C}$ ). F profiles were further divided based on their vesicle density; F1 profiles contained a high density of flattened vesicles and were strictly presynaptic (red profiles in Figure 1B and 2A,D,E), while F2 profiles contained a lower density of synaptic vesicles and were both presynaptic and postsynaptic (purple profiles in Figures 1B, 2E,F and 3A,B).

\section{Vesicle shape correlates with neurotransmitter content and synapse type}

In 1969, Guillery suggested that vesicle shape may correlate with neurotransmitter content, and indeed subsequent studies confirmed that F1 and F2 profiles contain GABA, while RLP and RSD profiles do not (Montero and Singer 1984; Montero 1991; Takács et al. 1991; Wang et al. 2001, 2002). Likewise, RSD and RLP profiles contain the type I and type II vesicular glutamate transporters (vGLUT1 and vGLUT2) respectively, while F profiles do not contain these proteins (Fujiyama et al. 2003; Bickford et al. 2008). Measurements of vesicle size and density also suggest precise relationships with neurotransmitter content and/or presynaptic proteins. A direct correlation was found between the density of GABA immunostaining and the density of synaptic vesicles in different $\mathrm{F}$ terminals (Montero 1991; Takács et al. 1991). Takács et al. (1991) also revealed that the size of synaptic vesicles varied within F profiles. F2 profiles contained the largest vesicles, and F1 profiles could be further subdivided into two groups; one group (F1-1) had vesicles that were smaller than those within F2 profiles, while another group (F1-2) contained vesicles similar in size to those contained within F2 profiles. Differences in vesicle density have also been shown to be related to the presynaptic protein synapsin I. In mice and tree shrews, RSD terminals contain this protein, while RLP profiles do not (Kielland et al. 2006; Wei et al. 2011), and in mice, removal of synapsin 1 changes vesicle density within RSD profiles and alters the dynamics of glutamate release from these terminals (Kielland et al. 2006; Nikolaev and Heggelund 2015).

The unique neurotransmitter content of $\mathrm{F}$ and $\mathrm{R}$ profiles also correlates with the synaptic contacts they form; the postsynaptic density associated with F1 and F2 synapses is approximately the thickness of the presynaptic density (symmetric synapse), while the postsynaptic density associated with RLP and RSD profiles is thicker than the presynaptic density (asymmetric synapse). Presumably these ultrastructural differences reflect the various postsynaptic receptors and other proteins associated with each type of synapse (Tarusawa et al. 2009).

\section{Adhesive junctions}

Finally, Guillery noted differences in the distribution of filamentous, or adhesive contacts between various profiles of the dLGN. Filamentous contacts are formed primarily between RLP profiles and their postsynaptic targets, F2 profiles and their postsynaptic targets, and occasionally between dendritic appendages that do not contain any vesicles (Figure 1B, arrowheads); filamentous contacts are never formed by RSD or F1 profiles. Thalamic filamentous contacts do not have synaptic vesicles associated with them (Patel and Bickford 1997; Bickford et al. 2010), and appear similar to the puncta adherentia of mossy fibers of the hippocampus, which are separate from the active zones of these terminals (Rollenhagen 
et al. 2007). It has been suggested that puncta adherentia could serve to either enhance or prevent synaptic spillover, depending on the placement of these adherent contacts relative to active zones (Rollenhagen et al. 2007).

\section{The retina is the sole source of RLP profiles}

By 1969, it had already been established that RLP profiles originate from the retina, based on degeneration studies (Szentágothai et al. 1966). Labeling of retinogeniculate axons combined with electron microscopy subsequently confirmed that all labeled profiles contained relatively pale mitochondria (Hamos et al. 1987; Feig et al. 1992; Datskovskaia et al. 2001; Dankowski and Bickford 2003). Interestingly, all retinorecipient regions of the brain contain terminals with "pale" mitochondria, and it is now well established that this unique ultrastructure can be used to identify retinal terminals (Behan 1982; Mize 1983; Mize and Horner 1984; Mize and Butler 1996). However, it is possible that a small percentage of retinal terminals contain dark mitochondria (Chen et al. 1996; Mize 1983; Chen and Pourcho 1995), and in the mouse and tree shrew, pale mitochondria cannot be identified prior to postnatal day 14 (Brunso-Bechtold and Casagrande 1985; Bickford et al. 2010). The particular reason that retinal terminals contain mitochondria with sparse cristae has never been explained. Wide variations in the configuration of mitochondria cristae have been noted (Zick et al. 2009), and it has been suggested that retinal ganglion cells are particularly sensitive to mitochondrial dysfunction (Ito and Di Polo 2017).

\section{RSD profiles originate from the cortex and brainstem}

Guillery identified the cortex as a source of RSD profiles based on correlations with the size of boutons emanating from the type I axons, as well as the results of degeneration studies (Jones and Powell 1969). At the time, it was noted that many RSD profiles persisted even after total hemidecortication, which suggested that profiles with RSD morphology also included terminals of subcortical origin. A cholinergic/nitrergic input from the brainstem was later identified as a source of approximately half of the RSD profiles in the A lamina of the dLGN (Fitzpatrick et al. 1989; Raczkowski and Fitzpatrick 1989; Bickford et al. 1993; Erişir et al 1997a; 1997b). As a population, cholinergic terminals are slightly larger than the overall population of RSD profiles, and as discussed below, RSD profiles originating from the cortex and brainstem target different synaptic zones. The parabigeminal nucleus likely provides a major source of RSD input to the C lamina (Fitzpatrick et al. 1989b; Feig et al. 1992). Other minor sources of RSD profiles may arise from serotoninergic and noradrenergic brainstem inputs (De Lima and Singer 1987; Bickford et al. 1993).

\section{F2 profiles originate from the dendrites of intrinsic interneurons (class III cells)}

The dendritic origin of $\mathrm{F} 2$ profiles was first established via ultrastructural reconstructions of images collected from serial sections (Famiglietti and Peters 1972). The definitive origin of F2 profiles from the dendrites of class III cells was subsequently determined by examining the ultrastructure of a class III cell that was intracellularly filled with horseradish peroxidase during recording (Hamos et al. 1985), as well as Golgi-stained class III cells (Montero 
1986b, 1987). F2 profiles were found to originate from the dendritic appendages of class III cells. As predicted by Guillery, class III cells are intrinsic interneurons; they do not project outside the dLGN, and they contain GABA (Montero 1986a, 1986b). Intrinsic GABAergic interneurons make up approximately $20 \%$ of the neurons in the dLGN, and the majority of these cells are likely to be class III cells, based on the size of their somata (Weber and Kalil 1983; Montero 1986a, 1986b). In contrast, class I, II and IV cells project outside the dLGN, to the cortex and thalamic reticular nucleus, and are therefore defined as "relay cells" (Friedlander et al. 1981).

As described by Guillery, F2 dendritic appendages are both presynaptic and postsynaptic; they receive input from RLP profiles, F profiles, and occasional RSD profiles. The interneuron investigated by Hamos et al (1985) also received input from large profiles that contain round vesicles and dark mitochondria (RLD profiles, described below). The postsynaptic targets of F2 profiles are primarily the dendrites of class I or II cells in the A lamina (Wilson et al. 1984; Hamos et al. 1985, 1987; Datskovskaia et al. 2001), or the dendrites of class I or IV cells in the C lamina (Raczkowski et al. 1988; Dankowski and Bickford 2003).

Whether F2 profiles contact other interneurons has been difficult to address. This is because, as noted by Guillery (1969a), the vesicle density differences between F1 and F2 profiles are not always conspicuous. In addition, as described below, the vesicles in the axons of interneurons are not as densely distributed as are vesicles in typical F1 profiles (Montero 1987). Therefore, the dendritic terminals of interneurons can only be definitively identified as postsynaptic vesicle-filled profiles. Thus, in many studies, F1 and F2 profiles are combined as a single F category (Hamos et al. 1985; Montero 1991; Erişir et al. 1998; Van Horn et al. 2000).

\section{F1 profiles originate from the pretectum and thalamic reticular nucleus}

Two extrinsic sources of GABAergic input to the dLGN have been identified: the thalamic reticular nucleus (TRN) and the pretectum; these sources have both been found to innervate the dLGN with axon terminals that display the ultrastructural features of F1 profiles described by Guillery (Wang et al. 2001, 2002). By examining these terminals in tissue stained for GABA, it was found that terminals originating from the TRN almost exclusively innervate relay cells, while terminals originating from the pretectum innervate interneurons, including F2 profiles. These results suggest that the TRN and pretectum have opposing effects on the dLGN, with the TRN providing direct inhibition of relay cells and the pretectum providing disinhibition of relay cells.

\section{F1-like profiles originate from the axons of intrinsic interneurons}

The axonal output of class III cells was studied using Golgi impregnations of 3 cells (Montero 1987). Hamos et al (1985) also noted that a myelinated axon originated from an HRP-filled class III cell, but this axon lost its myelin 50 microns from the soma and was not followed further. The axonal terminals of the Golgi-impregnated class III cells studied by Montero (1987) were found to be only presynaptic, and thus are not identified as F2 profiles. 
However, it was noted that these profiles did not contain the dense accumulation of vesicles found within the classic F1 profiles identified by Guillery (1969a). The axon terminals of the class III cells contacted dendritic appendages and shafts; they never contacted F2 profiles. Takács et al. (1991; described above) suggested that their F1-2 profiles may originate from the axons of interneurons because the size of the vesicles within these profiles was similar to that found in F2 profiles. However, F1-2 profiles were found to contact F2 profiles, which was not found to be the case for the class III axon terminals. Therefore, it is possible that the F1-1 and F1-2 distinction may be related to differences in the ultrastructure of terminals originating from the TRN and pretectum.

\section{Identification of additional interneuron subtypes}

The existence of more than one type of GABAergic interneuron in the cat dLGN has been deduced by a variety of observations. First, it was noted that, as a population, GABAergic cells are smaller than class I, II, and IV cells, but there are many GABAergic neurons that are larger than class III cells (Montero and Zempel 1985; Montero 1986b; Sherman and Friedlander 1988). Second, immunocytochemical stains for calcium-binding proteins have suggested that, although all interneurons in the cat dLGN contain parvalbumin, a subset of interneurons also contain calbindin (Stichel et al. 1988; Demeulemeester et al. 1991). Third, a variety of dendrodendritic contacts that are not attributable to class III neurons have been described (Figure 2B,C; Famiglietti 1970; Rapisardi and Miles 1984; Hamos et al. 1985).

Finally, in addition to the four cell types described by Guillery, several authors noted the existence of a fifth class of cell with unique morphologic characteristics (Famiglietti 1970; Updyke 1979; Hitchcock and Hickey 1983; Bickford et al. 1999). Class V cells are small to medium-sized cells that extend three to eight small caliber, often beaded, dendrites. Their dendritic fields are large and often cross nuclear or laminar boundaries. It was found that immunocytochemical staining for nitric oxide synthase or histochemical staining for NADPH-diaphorase, labeled these class V cells (Bickford et al. 1999). Ultrastructural studies of class $\mathrm{V}$ cells in tissue stained for GABA revealed that these cells were GABAergic and their dendritic shafts contained small collections of vesicles that provided dendrodendritic contacts in the interstitial neuropil (Erişir et al., 1997a, 1997b, Bickford et al. 1999).

\section{Identification of additional terminal types: RM and RLD profiles}

Two additional terminal types have been identified in the dLGN. A large profile with sparsely distributed round vesicles and dark mitochondria (RLD profile, Figure 3D) is a relatively rare terminal type that has been noted in a variety of studies of the cat dLGN (Hamos et al. 1985; Montero 1989a; Bickford et al. 2008). These terminals, which express vGLUT2, contact relay cell dendrites and F2 profiles and are primarily located in the interlaminar zones. RLD profiles likely originate from the axon collaterals of relay cells, based on their distribution, the fact that other terminal sources do not display the RLD ultrastructure (Montero 1989b), and in one instance, labeling from an intracellular injection of HRP in a single relay cell (Hamos 1990). In addition, dLGN terminals of medium size (RM profiles, i.e. larger than RSD profiles but smaller than RLP profiles) have been found to 
originate from the superior colliculus in the cat, as well as other species (Robson and Hall 1977; Torrealba et al. 1981; Feig and Harting 1994; Bickford et al. 2015). Tectogeniculate terminals are similar to retinogeniculate terminals in that they contact both $\mathrm{F} 2$ profiles and relay cell dendrites, and they can converge with retinogeniculate terminals to innervate single relay cells. In the cat, these terminals are located in the parvocellular $\mathrm{C}$ lamina (Torrealba et al. 1981; Harting et al. 1991).

\section{Synaptic arrangements: encapsulated and interstitial zones}

Guillery (1969a) described two distinct regions of the dLGN neuropil. Encapsulated zones, or glomeruli, are areas in which RLP profiles, F2 profiles and relay cell dendrites connect with one another in complex synaptic relationships (Figures 1 and 3A, B, Table 1, dark gray shading). As described above, within these zones, in addition to synaptic connections, the RLP, F2 and relay cell dendrites are attached to one another via filamentous (presumed adhesive) junctions. Therefore, these profiles are tightly entwined and no glial processes are seen between them. Instead, glial lamellae can occasionally be seen to surround the outer perimeter of this unique tangle of synaptic connections. This arrangement has been proposed to contribute to retinogeniculate synaptic dynamics by reducing the clearance of glutamate, resulting in the desensitizing of AMPA receptors and a depression of synaptic responses (Tarusawa et al. 2009; Budisantoso et al. 2012).

The most interesting arrangement found within encapsulated zones is the synaptic triad. Within a synaptic triad, an F2 profile (dendritic terminal originating from a GABAergic interneuron) is innervated by an RLP profile (retinogeniculate terminal), and the interconnected F2 and RLP profiles both contact the same relay cell dendrite. Although it is rare to observe all the synapses connecting these 3 components in single sections, serial section analyses have demonstrated that triadic arrangements are quite common within encapsulated zones (Rapisardi and Miles 1984; Hamos et al. 1985, 1987). Triadic synaptic relationships are thought to provide precise local feedforward inhibition of relay cell dendrites, because $\mathrm{F} 2$ profiles can release neurotransmitter without the generation of action potentials (Cox and Beatty 2017).

The complexity of triads varies, from simple, "low triads" in which a single a RLP profile, F2 profile and relay cell dendrite interconnect, to complex "high triads", in which multiple RLP profiles, F2 profiles, and relay cell dendritic appendages interconnect (Rapisardi and Miles 1984). The complexity of triads is related to the type of postsynaptic cell. Simple triads are associated with class I cells and complex triads are associated with class II cells (Wilson et al. 1984; Hamos et al. 1985, 1987). The encapsulated zones are most conspicuous when triads are complex; simple triads may also be encapsulated by surrounding glial lamella, but these arrangements are not strikingly different from the surrounding interstitial zones, described below.

Between the large, complex, encapsulated zones are the interstitial zones (Figure 2A, B and 3C, Table 1 light gray shading). In these areas, filamentous contacts are rarely seen, and glial lamella can surround individual terminals. RSD profiles that originate from the cortex and $\mathrm{F} 1$ profiles that originate from the TRN predominate in the interstitial zones, where they 
make simple synaptic contacts on the dendritic shafts of relay cells (Erişir et al., 1997a). Dendrites postsynaptic to the cortical and TRN terminals are generally smaller than those associated with RLP and F2 contacts: dendrites proximal to the soma are more frequent targets of RLP and F2 profiles and distal dendrites receive more RSD and F1 inputs (Wilson et al. 1984).

RSD and F1 inputs can also be found within encapsulated zones (Figure 1, 2C). The RSD profiles in encapsulated zones primarily arise from brainstem cholinergic/nitrergic cells (Erişir et al., 1997b); these cholinergic/nitrergic RSD terminals contact both F2 profiles and relay cell dendrites. F1 profiles within encapsulated zones originate from the pretectum and contact $\mathrm{F} 2$ profiles (Wang et al. 2002). Terminals that originate from interneuron axons may also contribute to the $\mathrm{F} 1$ profiles within interstitial zones; as described above, terminals originating from class III cells have not been observed to contact F2 profiles (Montero 1987).

\section{Receptor distribution}

Reflecting the different distributions of terminal types within the encapsulated and interstitial zones, different distributions of neurotransmitter receptors have been identified in each. Within encapsulated zones, muscarinic type 2 receptors are densely distributed on F2 profiles, where they can be activated by acetylcholine released from RSD profiles (Carden and Bickford 1999; Plummer et al. 1999). Type 5 metabotropic receptors are also densely distributed on F2 profiles (Godwin et al. 1996), where they can be activated by glutamate released from RLP profiles. Within the interstitial zones, type 1 alpha metabotropic receptors are distributed on relay cell dendrites, where they can be activated by glutamate released from cortical RSD profiles (Godwin et al. 1996). Finally, while ionotropic AMPA and NMDA receptors are postsynaptic to both cortical RSD and retinal RLP synapses, quantitative measurements in rats indicate that NMDA receptors are more densely distributed postsynaptic to cortical RSDs (Tarusawa et al. 2009).

\section{Proportions of terminal types and their synaptic connections}

A quantitative analysis of terminal types accompanied Guillery's 1969 classic description of terminals types in the dLGN (Guillery 1969b). In this companion paper, Guillery analyzed 2700 synapses in the A laminae of the dLGN. He found that $20 \%$ of the synapses were formed by RLP profiles, 35\% by F profiles, and $45 \%$ were formed by RSD profiles. $25 \%$ of the RLP synapses were found to contact F2 profiles, and 75\% contacted dendrites.

Approximately half of the synapses in the dLGN A laminae were found in encapsulated zones, and half were located in the interstitial zones. However, it was noted that the regions of the dLGN receiving input from the central retinal contained more encapsulated zones than regions receiving input from the peripheral retina.

Later studies, using tissue stained to reveal GABA, revealed similar proportions of synapses. In an analysis of 1191 synaptic terminals in the A and A1 laminae, Erişir et al. (1998) observed the following proportions: RLP 18\%, F $29 \%$ and RSD 53\%. Further analysis revealed that relative to lamina A1, lamina A contained a slightly lower proportion of RSD 
terminals and a higher proportion of $\mathrm{F}$ terminals, but the proportion of RLP terminals did not differ significantly between lamina. A subsequent study more accurately determined the proportions of each synapse type in the dLGN A lamina by taking into account the size of each terminal type, and the length of their synaptic zones. This analysis revealed the following proportions of synapses in the A lamina: $11.7 \% \mathrm{RLP}, 27.5 \% \mathrm{~F}$, and $60.8 \% \mathrm{RSD}$ (Van Horn et al. 2000). Finally, by taking into account the number of synapses formed by each terminal type ( 1 synapse per RSD, 9 synapses per RLP, and 2.5 synapses per F) the overall percentages of each terminal type were found to be: RLP 1.8\%, F 14.5\%, and RSD 83.7\% (Van Horn et al. 2000). Similar proportions were identified by Wilson et al. (1984), who intracellularly labeled 4 relay cells (2 physiologically characterized as X cells and 2 as Y cells) and analyzed their synaptic inputs by sampling approximately $10 \%$ of the dendritic arbor of each cell (including regions proximal and distal to the soma). On proximal dendrites of all cells, RLP terminals were found to provide $15-25 \%$ and $\mathrm{F}$ terminals $30-55 \%$ of the total synapses. On distal dendrites (greater than 100 microns from the soma), $\mathrm{F}$ terminals provided $10-20 \%$ and RSD terminals $60-80 \%$ of the total synapses. In summary, all studies indicate that RSD profiles are the most common terminal type, and they predominate on distal dendrites of relay cells. RLP profiles are the least common terminal type, and they predominate on proximal dendrites of relay cells. F profiles make up approximately one third of the synapses in the dLGN A laminae, and they predominate on the proximal dendrites of relay cells.

GABA stained tissue has also been used to determine the proportion of terminal types that synapse on relay cells versus interneurons. Montero et al (1991) analyzed 4003 synapses in the A lamina of the dLGN and found that interneurons received the following relative percentages of synapses: retinal $25 \%$, cortical $37 \%$, GABAergic $26 \%$, axon collaterals $2 \%$, undetermined $6 \%$. In contrast, relay cells received less retinal input and greater cortical input (retinal 12\%, cortical 58\%, GABAergic 24\%, axon collaterals $0.3 \%$, undetermined 5\%). Van Horn et al (2000) also found that relative to relay cells, interneurons receive more input from RLP profiles, and less input from RSD profiles (interneurons: RLP 48.7\%, F 24.4\%, and RSD 26.9\%, relay cells: RLP 7.1\%, F 30.9\%, and RSD 62.0\%).

Finally, Montero (1991) found that the vast majority of RLP input to interneurons synapsed on $\mathrm{F} 2$ profiles rather than on their dendritic shafts, while interneuron dendritic shafts received the majority of their input from cortical terminals. Thus, it was suggested that F2 profiles and the presynaptic dendritic shafts of interneurons form two different microcircuits that are under retinal and cortical control respectively. It is possible that these microcircuits involve different types of interneurons: class III interneuron primarily receive input from retinal terminals within encapsulated zones (Hamos et al. 1985) while class $V$ cells primarily receive input from cortical terminals within interstitial zones (Bickford et al. 1999; Carden and Bickford 2002).

\section{Convergence/divergence}

Wilson et al. (1984) estimated that relay cells receive 4000-5000 total synaptic contacts: 300-600 from RLP terminals, 1800-2000 from F terminals, and 1900-2600 from RSD terminals. Thus, convergent inputs are likely common, dependent on the number of synapses 
provided by individual axon arbors innervating each cell. Robson (1993) examined the innervation patterns of retinogeniculate axons (labeled by HRP injections in the optic tract) onto class I cells (labeled by HRP injections in the optic radiation). Labeled class I cells received synapses from both labeled and unlabeled retinal terminals, indicating that they receive convergent innervation from more than one ganglion cell. It was estimated that each cell received input from 10 or more retinal axons and that each retinal axon diverged to innervate more than 20 relay cells.

Hamos et al. (1987) examined the synaptic targets of an HRP-filled retinogeniculate axon identified by its physiological properties as originating from an X ganglion cell. Approximately $18 \%$ of the terminal arbor was examined at the ultrastructural level in serial sections. This region of the axon arbor contacted 4 relay cells; these cells received varying proportions of their retinal input from this labeled axon $(2 \%, 33 \%, 49 \%$ or $100 \%)$. Thus, this study demonstrated that the convergence of retinal axons on individual relay cells can vary widely. Interestingly, while most of the labeled retinogeniculate terminals participated in triads, the complexity of glomeruli varied considerably; for the cell that received $100 \%$ of its input from the labeled axon, all of the retinogeniculate boutons participated in complex "high triads", while the arrangements of the labeled retinogeniculate terminals on the other 3 cells were classified as simple "low triads". The complex "high triads" likely involve a great deal of interneuron convergence. Hamos et al. (1985) also reconstructed a class III interneuron dendritic arbor, and its complex relationship with the dendritic appendages of its postsynaptic relay cell. This analysis revealed that the labeled interneuron contributed only a fraction of the F2 synaptic inputs to the reconstructed cluster of relay cell dendritic appendages ( 9 synapses of $40 \mathrm{~F}$ profiles, 23 of which could clearly be defined as F2 profiles). These combined results, although limited, suggest that retinogeniculate convergence could be inversely related to interneuron convergence.

\section{Future directions}

A half century after Ray Guillery's classic descriptions of cell types, axon types, and synaptic architecture of the dLGN, the functional organization of this nucleus, as well as all other thalamic nuclei, is still of enormous interest. A variety of technical advances have made it possible to delve into thalamic circuit organization with unprecedented detail. Perhaps most relevant to Ray Guillery's initial observations are the advances in ultrastructural studies that enable the reconstruction of large areas of tissue by scanning serial block faces or sections. Such studies have used Ray Guillery's classic descriptions of profile types to identify retinogeniculate convergence patterns (Hammer et al. 2015; Morgan et al. 2016). The challenge now will be to combine these powerful reconstruction techniques with the equally powerful advances in techniques to label specific synaptic elements within the dLGN. A particularly exciting advance is the generation of a peroxidase reporter mouse line (Takeno et al. 2017). This line expresses an engineered peroxidase under the influence of cre-recombinase and a tetracycline-responsive promoter element; when these factors are introduced via breeding or virus injections, various elements can be labeled with electron dense markers. Equally powerful advances include optogenetic and chemogenetic techniques, which make it possible to activate/inactive specific circuit components for detailed correlative studies of structure and function. 
The major terminal types defined by Guillery in the cat have been clearly identified in the dLGN of a variety of mammalian species (Robson and Hall 1975; Brunso-Bechtold and Casagrande 1985; Wilson 1986, 1989, 1993; Feig and Harting 1994b; Li et al. 2003;

Bickford et al. 2010; Day-Brown et al. 2017), emphasizing the utility of the nomenclature he introduced. However, given the variety of laminar configurations and variations in the morphology of cell types seen across species, the precise configurations of terminal types likely vary considerably with species. Comparative studies are needed to determine how variations in dLGN circuits correlate with species-specific visual capabilities. For example, recent studies suggest that the mouse may exhibit more convergence of retinal inputs when compared to cats (Chen et al. 2016). However, at this point it is unclear whether this is a true species-specific difference, or a more universal feature newly revealed by technical advances. A definitive answer awaits direct species comparisons using identical techniques. Likewise, the morphologies of intrinsic GABAergic interneurons in rodents are distinct from the class III interneurons identified by Guillery in the cat (Hamos et al. 1985; Williams et al. 1996; Zhu and Uhlrich 1998; Zhu et al. 1999). Therefore, the synaptic arrangements of F2 profiles may vary considerably across species. Again, comparative studies are needed in order to understand the various ways in which geniculate inhibition can hone visual signals. A clear demonstration of the power of comparative studies can be found in Guillery's careful observations of a wide variety of pigmented and albino species (Guillery 1996; also reviewed in this issue). We can honor Ray Guillery by continuing to unravel the "enchanted loom" (Sherrington 1940) of the dLGN, using emerging technical advances, as well as species comparisons, to further build upon his initial observations. Insight and inspiration can certainly be found by reading the original classic studies discussed in this review.

\section{Acknowledgments}

This work was supported by the National Eye Institute (R01EY024173), National Institute of Neurological Disorders and Stroke (R21NS104807) and the Kentucky Biomedical Research Infrastructure Network (P20GM103436). Special thanks to Arkadiusz Slusarczyk for preparation of tissue for electron microscopy.

\section{References}

Behan M. 1982; A quantitative analysis of the ipsilateral retinocollicular projection in the cat: An EM degeneration and EM autoradiographic study. J Comp Neurol. 206:253-258. [PubMed: 7085932]

Bickford ME. 2016; Thalamic Circuit Diversity: Modulation of the Driver/Modulator Framework. Front Neural Circuits. 9:86. [PubMed: 26793068]

Bickford ME, Carden WB, Patel NC. 1999; Two types of interneurons in the cat visual thalamus are distinguished by morphology, synaptic connections, and nitric oxide synthase content. J Comp Neurol. 413:83-100. [PubMed: 10464372]

Bickford ME, Guido W, Godwin DW. 1998; Neurofilament proteins in Y-cells of the cat lateral geniculate nucleus: normal expression and alteration with visual deprivation. J Neurosci. 18:65496557. [PubMed: 9698342]

Bickford ME, Günlük AE, Guido W, Sherman SM. 1993; Evidence that cholinergic axons from the parabrachial region of the brainstem are the exclusive source of nitric oxide in the lateral geniculate nucleus of the cat. J Comp Neurol. 334:410-430. [PubMed: 7690785]

Bickford ME, Slusarczyk A, Dilger EK, Krahe TE, Kucuk C, Guido W. 2010; Synaptic development of the mouse dorsal lateral geniculate nucleus. J Comp Neurol. 518:622-635. [PubMed: 20034053]

Bickford ME, Wei H, Eisenback MA, Chomsung RD, Slusarczyk AS, Dankowsi AB. 2008; Synaptic organization of thalamocortical axon collaterals in the perigeniculate nucleus and dorsal lateral geniculate nucleus. J Comp Neurol. 508:264-285. [PubMed: 18314907] 
Bickford ME, Zhou N, Krahe TE, Govindaiah G, Guido W. 2015; Retinal and Tectal "Driver-Like" Inputs Converge in the Shell of the Mouse Dorsal Lateral Geniculate Nucleus. J Neurosci. 35:10523-10534. [PubMed: 26203147]

Brunso-Bechtold JK, Casagrande VA. 1985; Ultrastructure of the developing tree shrew lateral geniculate nucleus. Brain Res. 355:310-314. [PubMed: 4084788]

Budisantoso T, Matsui K, Kamasawa N, Fukazawa Y, Shigemoto R. 2012; Mechanisms underlying signal filtering at a multisynapse contact. J Neurosci. 32:2357-2376. [PubMed: 22396411]

Carden WB, Bickford ME. 1999; Location of muscarinic type 2 receptors within the synaptic circuitry of the cat visual thalamus. J Comp Neurol. 410:431-443. [PubMed: 10404410]

Carden WB, Bickford ME. 2002; Synaptic inputs of class III and class V interneurons in the cat pulvinar nucleus: differential integration of RS and RL inputs. Vis Neurosci. 19:51-59. [PubMed: 12180859]

Sherrington, Charles. Man on his Nature. Cambrige University Press; 1940.

Chen B, Hu XJ, Pourcho RG. 1996; Morphological diversity in terminals of W-type retinal ganglion cells at projection sites in cat brain. Vis Neurosci. 13:449-460. [PubMed: 8782372]

Chen B, Pourcho RG. 1995; Morphological diversity and glutamate immunoreactivity of retinal terminals in the suprachiasmatic nucleus of the cat. J Comp Neurol. 361:108-118. [PubMed: 8550873]

Chen C, Bickford ME, Hirsch JA. 2016Untangling the Web between Eye and Brain. Cell. :165. [PubMed: 26924576]

Cox CL, Beatty JA. 2017; The multifaceted role of inhibitory interneurons in the dorsal lateral geniculate nucleus. Vis Neurosci. 34:E017. [PubMed: 28965520]

Dankowski A, Bickford ME. 2003; Inhibitory circuitry involving Y cells and Y retinal terminals in the $\mathrm{C}$ laminae of the cat dorsal lateral geniculate nucleus. J Comp Neurol. 460:368-379. [PubMed: 12692855]

Datskovskaia A, Carden WB, Bickford ME. 2001; Y retinal terminals contact interneurons in the cat dorsal lateral geniculate nucleus. J Comp Neurol. 430:85-100. [PubMed: 11135247]

Day-Brown JD, Slusarczyk AS, Zhou N, Quiggins R, Petry HM, Bickford ME. 2017Synaptic organization of striate cortex projections in the tree shrew: A comparison of the claustrum and dorsal thalamus. J Comp Neurol. :525.

De Lima AD, Singer W. 1987; The serotoninergic fibers in the dorsal lateral geniculate nucleus of the cat: distribution and synaptic connections demonstrated with immunocytochemistry. J Comp Neurol. 258:339-351. [PubMed: 3294925]

Demeulemeester H, Arckens L, Vandesande F, Orban GA, Heizmann CW, Pochet R. 1991; Calcium binding proteins as molecular markers for cat geniculate neurons. Exp brain Res. 83:513-520. [PubMed: 2026194]

Erişir A, Van Horn SC, Sherman SM. 1997a; Relative numbers of cortical and brainstem inputs to the lateral geniculate nucleus. Proc Natl Acad Sci U S A. 94:1517-1520. [PubMed: 9037085]

Erişir A, Van Horn SC, Bickford ME, Sherman SM. 1997b; Immunocytochemistry and distribution of parabrachial terminals in the lateral geniculate nucleus of the cat: a comparison with corticogeniculate terminals. J Comp Neurol. 377:535-549. [PubMed: 9007191]

Erişir A, Van Horn SC, Sherman SM. 1998; Distribution of synapses in the lateral geniculate nucleus of the cat: differences between laminae A and A1 and between relay cells and interneurons. J Comp Neurol. 390:247-255. [PubMed: 9453668]

Famiglietti EV, Peters A. 1972; The synaptic glomerulus and the intrinsic neuron in the dorsal lateral geniculate nucleus of the cat. J Comp Neurol. 144:285-333. [PubMed: 4112778]

Famiglietti EV. 1970; Dendro-dendritic synapses in the lateral geniculate nucleus of the cat. Brain Res. 20:181-191. [PubMed: 4101880]

Feig S, Harting JK. 1994; Ultrastuctural studies of the primate lateral geniculate nucleus: Morphology and spatial relationships of axon terminals arising from the retina, visual cortex (area 17), superior colliculus, parabigminal nucleus, and pretectum of Galago crassicaudatus. J Comp Neurol. 343:17-34. [PubMed: 8027433] 
Feig S, Van Lieshout DP, Harting JK. 1992; Ultrastructural studies of retinal, visual cortical (area 17), and parabigeminal terminals within the superior colliculus ofGalago crassicaudatus. J Comp Neurol. 319:85-99. [PubMed: 1592907]

Fitzpatrick D, Diamond IT, Raczkowski D. 1989; Cholinergic and monoaminergic innervation of the cat's thalamus: Comparison of the lateral geniculate nucleus with other principal sensory nuclei. J Comp Neurol. 288:647-675. [PubMed: 2478594]

Fitzpatrick D, Penny GR, Schmechel DE. 1984; Glutamic acid decarboxylase-immunoreactive neurons and terminals in the lateral geniculate nucleus of the cat. J Neurosci. 4:1809-1829. [PubMed: 6376726]

Friedlander MJ, Lin CS, Stanford LR, Sherman SM. 1981; Morphology of functionally identified neurons in lateral geniculate nucleus of the cat. J Neurophysiol. 46:80-129. [PubMed: 7264710]

Fujiyama F, Hioki H, Tomioka R, Taki K, Tamamaki N, Nomura S, Okamoto K, Kaneko T. 2003; Changes of immunocytochemical localization of vesicular glutamate transporters in the rat visual system after the retinofugal denervation. J Comp Neurol. 465:234-249. [PubMed: 12949784]

Godwin DW, Van Horn SC, Eriir A, Sesma M, Romano C, Sherman SM. 1996; Ultrastructural localization suggests that retinal and cortical inputs access different metabotropic glutamate receptors in the lateral geniculate nucleus. J Neurosci. 16:8181-8192. [PubMed: 8987843]

Guillery RW. 1966; A study of Golgi preparations from the dorsal lateral geniculate nucleus of the adult cat. J Comp Neurol. 128:21-49. [PubMed: 4165857]

Guillery RW. 1969a; The organization of synaptic interconnections in the laminae of the dorsal lateral geniculate nucleus of the cat. Z Zellforsch Mikrosk Anat. 96:1-38. [PubMed: 5772028]

Guillery RW. 1969b; A quantitative study of synaptic interconnections in the dorsal lateral geniculate nucleus of the cat. Z Zellforsch Mikrosk Anat. 96:39-48.

Guillery RW. 1996; Why do albinos and other hypopigmented mutants lack normal binocular vision and what else is abnormal in their central visual pathways? Eye. 10:217-221. [PubMed: 8776451]

Guillery RW, Sherman SM. 2002; Thalamic relay functions and their role in corticocortical communication: generalizations from the visual system. Neuron. 33:163-175. [PubMed: 11804565]

Hammer S, Monavarfeshani A, Lemon T, Su J, Fox MA. 2015; Multiple Retinal Axons Converge onto Relay Cells in the Adult Mouse Thalamus. Cell Rep. 12:1575-1583. [PubMed: 26321636]

Hamos JE. 1990; Synaptic circuitry identified by intracellular labeling with horseradish peroxidase. J Electron Microsc Tech. 15:369-376. [PubMed: 2202794]

Hamos JE, Van Horn SC, Raczkowski D, Sherman SM. 1987; Synaptic circuits involving an individual retinogeniculate axon in the cat. J Comp Neurol. 259:165-192. [PubMed: 3584556]

Hamos JE, Van Horn SC, Raczkowski D, Uhlrich DJ, Sherman SM. 1985; Synaptic connectivity of a local circuit neurone in lateral geniculate nucleus of the cat. Nature. 317:618-621. [PubMed: 4058571]

Harting JK, Huerta MF, Hashikawa T, van Lieshout DP. 1991; Projection of the mammalian superior colliculus upon the dorsal lateral geniculate nucleus: organization of tectogeniculate pathways in nineteen species. J Comp Neurol. 304:275-306. [PubMed: 1707899]

Hitchcock PF, Hickey TL. 1983; Morphology of C-laminae neurons in the dorsal lateral geniculate nucleus of the cat: A Golgi impregnation study. J Comp Neurol. 220:137-146. [PubMed: 6643722]

Humphrey AL, Sur M, Uhlrich DJ, Sherman SM. 1985a; Termination patterns of individual X- and Ycell axons in the visual cortex of the cat: Projections to area 18, to the 17/18 border region, and to both areas 17 and 18. J Comp Neurol. 233:190-212. [PubMed: 3973101]

Humphrey AL, Sur M, Uhlrich DJ, Sherman SM. 1985b; Projection patterns of individual X- and Ycell axons from the lateral geniculate nucleus to cortical area 17 in the cat. J Comp Neurol. 233:159-189. [PubMed: 3973100]

Ito YA, Di Polo A. 2017; Mitochondrial dynamics, transport, and quality control: A bottleneck for retinal ganglion cell viability in optic neuropathies. Mitochondrion. 36:186-192. [PubMed: 28866056] 
Jones EG, Powell TP. 1969; An electron microscopic study of the mode of termination of corticothalamic fibres within the sensory relay nuclei of the thalamus. Proc R Soc London Ser B, Biol Sci. 172:173-185. [PubMed: 4388108]

Kielland A, Erisir A, Walaas SI, Heggelund P. 2006; Synapsin utilization differs among functional classes of synapses on thalamocortical cells. J Neurosci. 26:5786-5793. [PubMed: 16723536]

Li J, Wang S, Bickford ME. 2003; Comparison of the ultrastructure of cortical and retinal terminals in the rat dorsal lateral geniculate and lateral posterior nuclei. J Comp Neurol. 460:394-409. [PubMed: 12692857]

Majorossy K, Réthelyi M. 1968; Synaptic architecture in the medial geniculate body (ventral division). Exp brain Res. 6:306-323. [PubMed: 5721763]

Majorossy K, Réthelyi M, Szentágothai J. 1965; The large glomerular synapse of the pulvinar. J Hirnforsch. 7:415-432. [PubMed: 5832368]

Mize RR. 1983; Variations in the retinal synapses of the cat superior colliculus revealed using quantitative electron microscope autoradiography. Brain Res. 269:211-221. [PubMed: 6883080]

Mize RR, Butler GD. 1996; Postembedding immunocytochemistry demonstrates directly that both retinal and cortical terminals in the cat superior colliculus are glutamate immunoreactive. J Comp Neurol. 371:633-648. [PubMed: 8841915]

Mize RR, Horner LH. 1984; Retinal synapses of the cat medial interlaminar nucleus and ventral lateral geniculate nucleus differ in size and synaptic organization. J Comp Neurol. 224:579-590. [PubMed: 6725632]

Montero VM. 1986a; The interneuronal nature of GABAergic neurons in the lateral geniculate nucleus of the rhesus monkey: a combined HRP and GABA-immunocytochemical study. Exp brain Res. 64:615-622. [PubMed: 3026831]

Montero VM. 1986b; Localization of gamma-aminobutyric acid (GABA) in type 3 cells and demonstration of their source to F2 terminals in the cat lateral geniculate nucleus: a Golgielectron-microscopic GABA-immunocytochemical study. J Comp Neurol. 254:228-245. [PubMed: 3540041]

Montero VM. 1987; Ultrastructural identification of synaptic terminals from the axon of type 3 interneurons in the cat lateral geniculate nucleus. J Comp Neurol. 264:268-283. [PubMed: 3680632]

Montero VM. 1989a; The GABA-immunoreactive neurons in the interlaminar regions of the cat lateral geniculate nucleus: light and electron microscopic observations. Exp brain Res. 75:497-512. [PubMed: 2744108]

Montero VM. 1989b; Ultrastructural identification of synaptic terminals from cortical axons and from collateral axons of geniculo-cortical relay cells in the perigeniculate nucleus of the cat. Exp brain Res. 75:65-72. [PubMed: 2707357]

Montero VM. 1991; A quantitative study of synaptic contacts on interneurons and relay cells of the cat lateral geniculate nucleus. Exp brain Res. 86:257-270. [PubMed: 1756802]

Montero VM, Singer W. 1984; Ultrastructure and synaptic relations of neural elements containing glutamic acid decarboxylase $(\mathrm{GAD})$ in the perigeniculate nucleus of the cat. A light and electron microscopic immunocytochemical study. Exp brain Res. 56:115-125. [PubMed: 6381084]

Montero VM, Zempel J. 1985; Evidence for two types of GABA-containing interneurons in the Alaminae of the cat lateral geniculate nucleus: a double-label HRP and GABAimmunocytochemical study. Exp brain Res. 60:603-609. [PubMed: 2416585]

Morgan JL, Berger DR, Wetzel AW, Lichtman JW. 2016; The Fuzzy Logic of Network Connectivity in Mouse Visual Thalamus. Cell. 165:192-206. [PubMed: 27015312]

Murphy PC, Duckett SG, Sillito AM. 2000; Comparison of the laminar distribution of input from areas 17 and 18 of the visual cortex to the lateral geniculate nucleus of the cat. J Neurosci. 20:845-853. [PubMed: 10632614]

Nakajima Y, Reese TS. 1983; Inhibitory and excitatory synapses in crayfish stretch receptor organs studied with direct rapid-freezing and freeze-substitution. J Comp Neurol. 213:66-73. [PubMed: 6338061]

Nikolaev M, Heggelund P. 2015; Functions of synapsins in corticothalamic facilitation: important roles of synapsin I. J Physiol. 593:4499-4510. [PubMed: 26256545] 
Patel NC, Bickford ME. 1997; Synaptic targets of cholinergic terminals in the pulvinar nucleus of the cat. J Comp Neurol. 387:266-278. [PubMed: 9336228]

Plummer KL, Manning KA, Levey AI, Rees HD, Uhlrich DJ. 1999; Muscarinic receptor subtypes in the lateral geniculate nucleus: a light and electron microscopic analysis. J Comp Neurol. 404:408425. [PubMed: 9952356]

Raczkowski D, Fitzpatrick D. 1989; Organization of cholinergic synapses in the cat's dorsal lateral geniculate and perigeniculate nuclei. J Comp Neurol. 288:676-690. [PubMed: 2808755]

Raczkowski D, Hamos JE, Sherman SM. 1988; Synaptic circuitry of physiologically identified W-cells in the cat's dorsal lateral geniculate nucleus. J Neurosci. 8:31-48. [PubMed: 3339413]

Ralston HJ. 1969; The synaptic organization of lemniscal projections to the ventrobasal thalamus of the cat. Brain Res. 14:99-115. [PubMed: 5783118]

Ralston HJ, Herman MM. 1969; The fine structure of neurons and synapses in ventrobasal thalamus of the cat. Brain Res. 14:77-97. [PubMed: 5783117]

Rapisardi SC, Miles TP. 1984; Synaptology of retinal terminals in the dorsal lateral geniculate nucleus of the cat. J Comp Neurol. 223:515-534. [PubMed: 6715570]

Robson JA. 1993; Qualitative and quantitative analyses of the patterns of retinal input to neurons in the dorsal lateral geniculate nucleus of the cat. J Comp Neurol. 334:324-336. [PubMed: 8366199]

Robson JA. 1984; Reconstructions of corticogeniculate axons in the cat. J Comp Neurol. 225:193-200. [PubMed: 6725642]

Robson JA, Hall WC. 1975; Connections of layer VI in striate cortex of the grey squirrel (Sciurus carolinensis). Brain Res. 93:133-139. [PubMed: 49213]

Robson JA, Hall WC. 1977; The organization of the pulvinar in the grey squirrel (Sciurus carolinensis). II. Synaptic organization and comparisons with the dorsal lateral geniculate nucleus. J Comp Neurol. 173:389-416. [PubMed: 853144]

Robson JA, Mason CA. 1979; The synaptic organization of terminals traced from individual labeled retino-geniculate axons in the cat. Neuroscience. 4:99-111. [PubMed: 759988]

Rollenhagen A, Satzler K, Rodriguez EP, Jonas P, Frotscher M, Lubke JHR. 2007; Structural Determinants of Transmission at Large Hippocampal Mossy Fiber Synapses. J Neurosci. 27:10434-10444. [PubMed: 17898215]

Sherman SM, Friedlander MJ. 1988; Identification of X versus Y properties for interneurons in the Alaminae of the cat's lateral geniculate nucleus. Exp brain Res. 73:384-392. [PubMed: 3215314]

Sherman SM, Guillery RW. 1998; On the actions that one nerve cell can have on another: distinguishing "drivers" from "modulators". Proc Natl Acad Sci U S A. 95:7121-7126. [PubMed: 9618549]

Stichel CC, Singer W, Heizmann CW. 1988; Light and electron microscopic immunocytochemical localization of parvalbumin in the dorsal lateral geniculate nucleus of the cat: Evidence for coexistence with GABA. J Comp Neurol. 268:29-37. [PubMed: 3346382]

Sur M, Frost DO, Hockfield S. 1988; Expression of a surface-associated antigen on Y-cells in the cat lateral geniculate nucleus is regulated by visual experience. J Neurosci. 8:874-882. [PubMed: 3346725]

Szentagothai J. 1963; The structure of the synapse in the lateral geniculate body. Acta Anat (Basel). 55:166-185. [PubMed: 14101379]

Szentágothai J, Hámori J, Tömböl T. 1966; Degeneration and electron microscope analysis of the synaptic glomeruli in the lateral geniculate body. Exp brain Res. 2:283-301. [PubMed: 5957903]

Takács J, Hámori J, Silakov V. 1991; GABA-containing neuronal processes in normal and cortically deafferented dorsal lateral geniculate nucleus of the cat: an immunogold and quantitative EM study. Exp brain Res. 83:562-574. [PubMed: 2026198]

Takeno MM, Buchanan J, Bleckert A, Diagle T, Gwinn RP, Cobbs CS, Zeng HDCN. 2017; High contrast tissue preparation for large scale serial section electron microscopy of mice and humans. Soc Neurosci Abstr. 490:15.

Tarusawa E, Matsui K, Budisantoso T, Molnar E, Watanabe M, Matsui M, Fukazawa Y, Shigemoto R. 2009; Input-Specific Intrasynaptic Arrangements of Ionotropic Glutamate Receptors and Their Impact on Postsynaptic Responses. J Neurosci. 29:12896-12908. [PubMed: 19828804] 
Torrealba F, Partlow GD, Guillery RW. 1981; Organization of the projection from the superior colliculus to the dorsal lateral geniculate nucleus of the cat. Neuroscience. 6:1341-1360. [PubMed: 6167900]

Updyke BV. 1979; A Golgi study of the class V cell in the visual thalamus of the cat. J Comp Neurol. 186:603-619. [PubMed: 15116691]

Van Horn SC, Erişir A, Sherman SM. 2000; Relative distribution of synapses in the A-laminae of the lateral geniculate nucleus of the cat. J Comp Neurol. 416:509-520. [PubMed: 10660881]

Wang S, Bickford ME, Van Horn SC, Erisir a, Godwin DW, Sherman SM. 2001; Synaptic targets of thalamic reticular nucleus terminals in the visual thalamus of the cat. J Comp Neurol. 440:321341. [PubMed: 11745627]

Wang S, Eisenback M, Datskovskaia A, Boyce M, Bickford ME. 2002; GABAergic pretectal terminals contact GABAergic interneurons in the cat dorsal lateral geniculate nucleus. Neurosci Lett. 323:141-145. [PubMed: 11950513]

Weber AJ, Kalil RE. 1983; The percentage of interneurons in the dorsal lateral geniculate nucleus of the cat and observations on several variables that affect the sensitivity of horseradish peroxidase as a retrograde marker. J Comp Neurol. 220:336-346. [PubMed: 6643731]

Wei H, Masterson SP, Petry HM, Bickford ME. 2011; Diffuse and specific tectopulvinar terminals in the tree shrew: synapses, synapsins, and synaptic potentials. PLoS One. 6:e23781. [PubMed: 21858222]

Williams SR, Turner JP, Anderson CM, Crunelli V. 1996; Electrophysiological and morphological properties of interneurones in the rat dorsal lateral geniculate nucleus in vitro. J Physiol. 490(Pt 1): 129-147. [PubMed: 8745283]

Wilson JR. 1986; Synaptic connections of relay and local circuit neurons in the monkey's dorsal lateral geniculate nucleus. Neurosci Lett. 66:79-84. [PubMed: 3714116]

Wilson JR. 1989; Synaptic organization of individual neurons in the macaque lateral geniculate nucleus. J Neurosci. 9:2931-2953. [PubMed: 2769372]

Wilson JR. 1993; Circuitry of the dorsal lateral geniculate nucleus in the cat and monkey. Acta Anat (Basel). 147:1-13. [PubMed: 8337921]

Wilson JR, Friedlander MJ, Sherman SM. 1984; Fine structural morphology of identified X- and Ycells in the cat's lateral geniculate nucleus. Proc R Soc Lond B Biol Sci. 221:411-436. [PubMed: 6146984]

Zhu JJ, Uhlrich DJ. 1998; Cellular mechanisms underlying two muscarinic receptor-mediated depolarizing responses in relay cells of the rat lateral geniculate nucleus. Neuroscience. 87:767781. [PubMed: 9759965]

Zhu JJ, Uhlrich DJ, Lytton WW. 1999; Burst firing in identified rat geniculate interneurons. Neuroscience. 91:1445-1460. [PubMed: 10391450]

Zick M, Rabl R, Reichert AS. 2009; Cristae formation-linking ultrastructure and function of mitochondria. Biochim Biophys Acta. 1793:5-19. [PubMed: 18620004] 

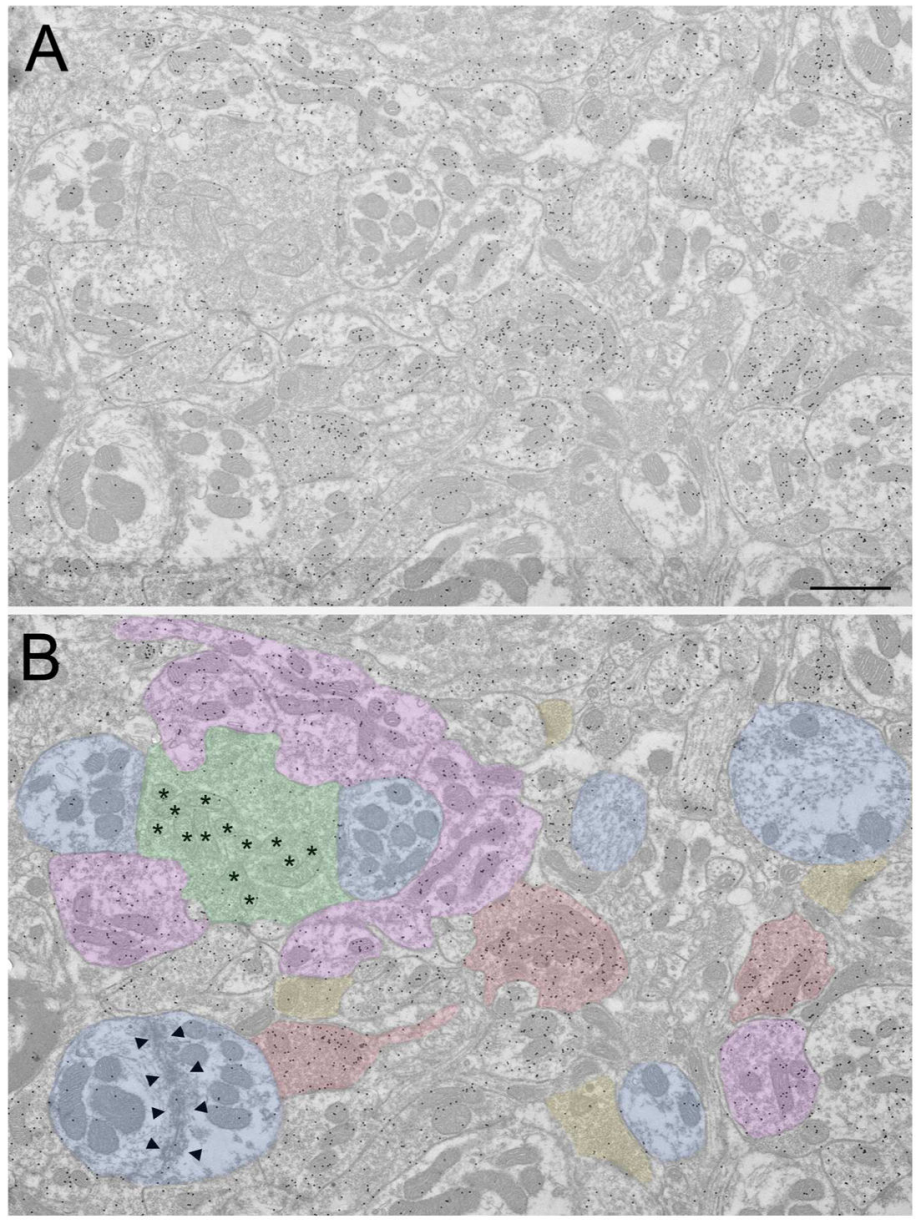

Figure 1.

Overview of terminal types in the cat dLGN. A) Electron micrograph of the A lamina of the cat dLGN. Tissue was previously used and prepared as described in Bickford et al. (2008); GABAergic terminals are identified by a high density of overlying gold particles. B) Same electron micrograph as shown in A, but with terminal types indicated with colors. Green: RLP (pale mitochondria indicated with asterisks), purple: F2, red: F1, yellow: RSD, blue: relay cell dendrite (adhesive contacts between 2 relay cell dendrites indicated by arrowheads). Scale bar $=1 \mathrm{Xm}$. 


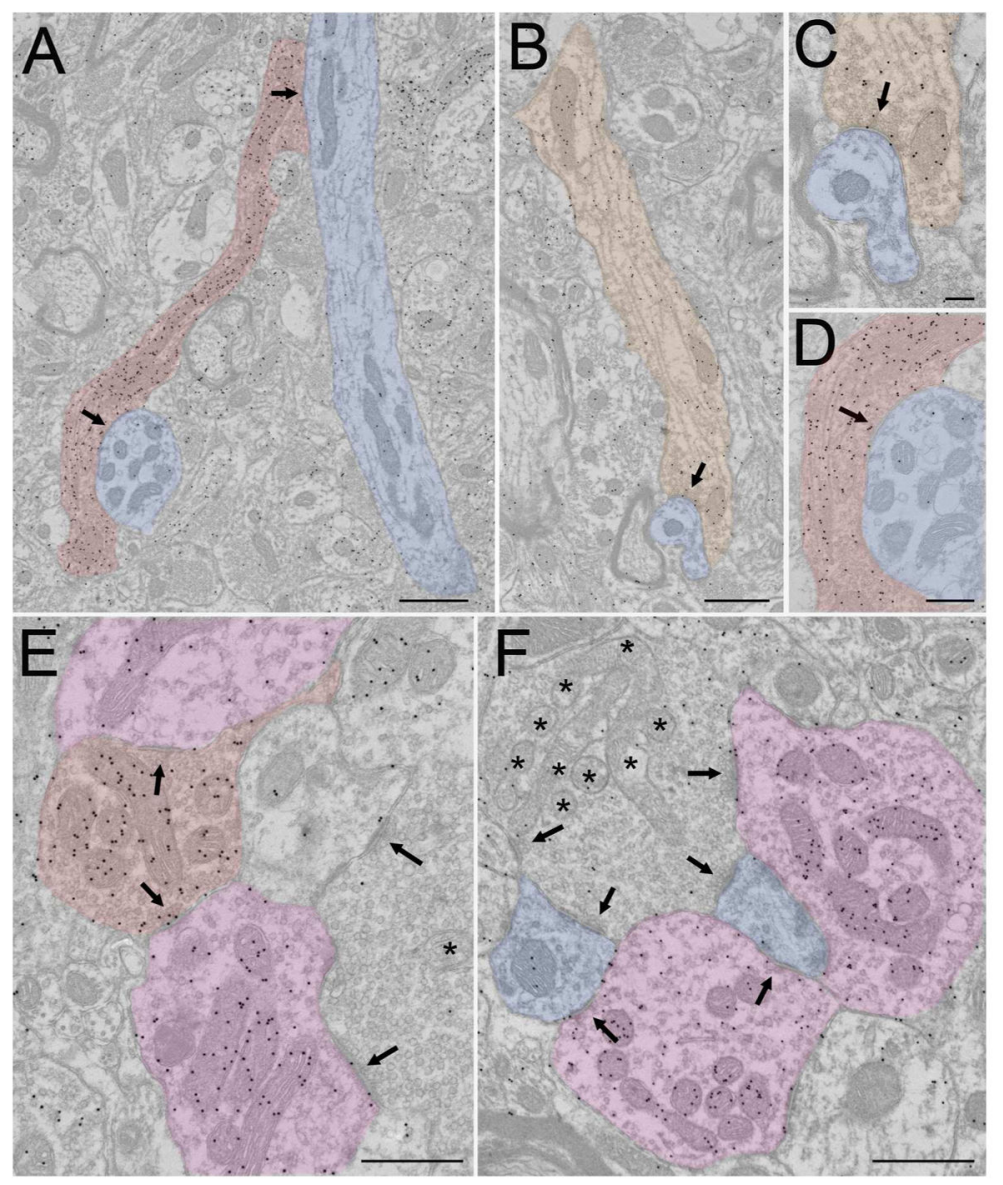

Figure 2.

GABAergic synaptic arrangements in the cat dLGN. In all panels synaptic contacts are indicated by arrows. A) An F1 profile (tinted red) contacts 2 relay cell dendrites (tinted blue). Scale bar $=1 \mathrm{Xm}$. The lower synapse in A is shown at higher magnification in panel D $($ scale $=400 \mathrm{~nm})$. B) An interneuron dendritic shaft (tinted orange) contacts a relay cell dendrite (blue, scale $=800 \mathrm{~nm}$ ). This synapse is shown at higher magnification in panel $\mathbf{C}$ $($ scale $=200 \mathrm{~nm})$. E) An F1 profile (tinted red) contacts 2 F2 profiles (tinted purple). The bottom F2 profile is also postsynaptic to an RLP profile (pale mitochondria indicated with an asterisk). Scale $=600 \mathrm{~nm}$. F) Presynaptic and postsynaptic arrangements of F2 profiles (tinted purple). The F2 on the right side is postsynaptic to an RLP profile (pale mitochondria indicated by asterisks). The bottom F2 profile contacts 2 relay cell dendrites (tinted blue) that are also postsynaptic to the RLP profile. Scale $=800 \mathrm{~nm}$. 

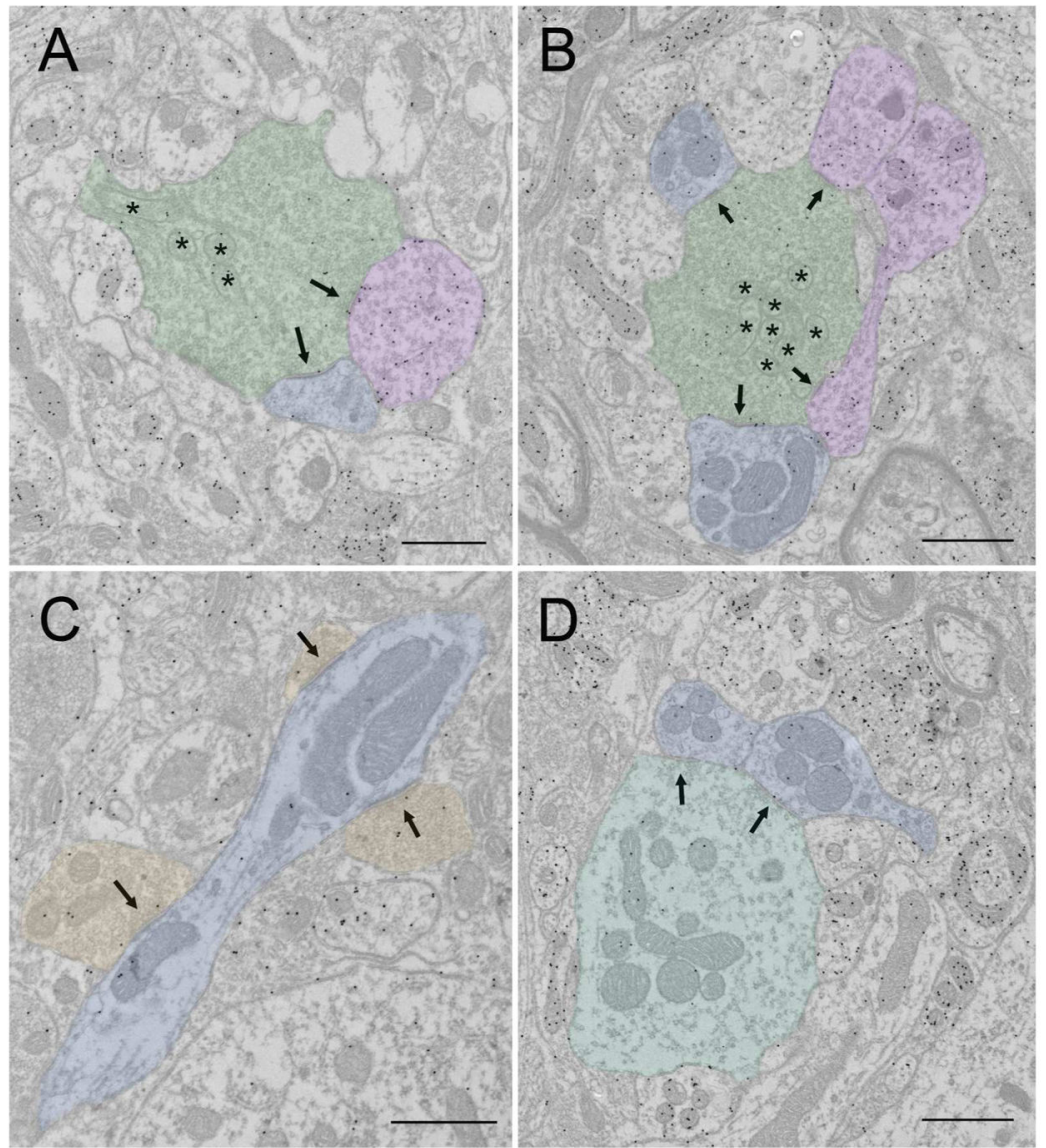

Figure 3.

Glutamatergic synaptic arrangements in the cat dLGN. In all panels synaptic contacts are indicated by arrows. A) An RLP profile (tinted green, pale mitochondria indicated by asterisks) contacts an F2 profile (tinted purple) and a relay cell dendrite (tinted blue). Scale $=800 \mathrm{~nm}$. B) An RLP profile (tinted green, pale mitochondria indicated by asterisks) contacts 2 F2 profiles (tinted purple) and 2 relay cell dendrites (tinted blue). Scale $=1 \mathrm{Xm}$. C) 3 RSD profiles (tinted orange) contact a relay cell dendrite (tinted blue). Scale bar $=800$ nm. D) An RLD profile (tinted blue-green) contacts 2 relay cell dendrites (tinted blue). Scale $=1 \mathrm{Xm}$. 


\section{Table 1}

Summary of synaptic profiles in the cat dLGN. Dark gray shading indicates synaptic profiles primarily located within encapsulated zones. Light gray shading indicated synaptic profiles primarily located within interstitial zones. See text for details.

\begin{tabular}{|l|l|l|l|l|}
\hline Source & Ultrastructure & Neurotransmitter & Presynaptic & Postsynaptic \\
\hline Retina & RLP & Glutamate (vGLUT2) & & Relay dendrite, F2 \\
\hline Class III dendrite & F2 & GABA & RLP, F, RSD & Relay dendrite \\
\hline Class III axon & F & GABA & & Relay dendrite \\
\hline Brainstem & RSD & Acetylcholine Nitric Oxide & & Relay dendrite, F2 \\
\hline Relay collateral & RLD & Glutamate (vGLUT2) & & Relay dendrite, F2 \\
\hline Pretectum & F1 & GABA & & Interneuron dendrite, F2 \\
\hline Superior colliculus & RM & Glutamate & & Relay dendrite, F2 \\
\hline Cortex & RSD & Glutamate (vGLUT1) & & Relay dendrite Class V dendrite \\
\hline TRN & F1 & GABA & & Relay dendrite \\
\hline Class V dendrite & Shaft with vesicles & GABA & RSD & Relay dendrite \\
\hline
\end{tabular}

